\title{
The effect of China's new cooperative medical scheme on health expenditures among the rural elderly
}

\author{
Yanbing Zeng ${ }^{1}$, Jiajing $\mathrm{Li}^{2}$, Zhipeng Yuan ${ }^{1}$ and Ya Fang ${ }^{*}$
}

\begin{abstract}
Background: The alarming progression of an increasingly aging population in China has attracted much attention within the country and abroad. In 2003, the Chinese central government launched the New Cooperative Medical Scheme (NCMS) to resolve problems of healthcare inequity in regions with inadequate infrastructure and relative poverty. The purpose of this study was to investigate the effect of NCMS on health expenditures by the Chinese rural elderly population.
\end{abstract}

Methods: The data were obtained from the Chinese Longitudinal Healthy Longevity Survey (CLHLS), which was conducted in 2005, 2008, 2011 and 2014. Elderly people living in rural areas and 60 years old or above were screened for the investigation. The sample size was 7472 in 2005, 11,705 in 2008, 9239 in 2011, and 6059 in 2014. The OOP\% and reimbursement ratio were the medical expenses paid by individuals accounting for their per capita annual income and the medical expenses paid by medical insurance accounting for their total medical expenses, respectively. By controlling for individuals' sociodemographic characteristics, pensions, demands and utilization of health services, we estimated the effect of the NCMS on the OOP\% and reimbursement ratio for the rural elderly using seemingly unrelated regression (SUR).

Results: The NCMS coverage ranged from 11.63\% in 2005 to $80.34 \%$ in 2014. The medical expenses of the elderly also increased from an average of \$204.77 in 2005 to $\$ 696.23$ in 2014, which was more than three times as much as in 2005. From 2005 to 2014, the reimbursement ratio for medical expenses of rural elderly people with NCMS increased significantly from $30.6 \%$ in 2005 to $56.1 \%$ in 2014. The proportion of reimbursement ratio for rural seniors with NCMS increased by $6.4 \%$ across each survey cycle (every 3 years). However, the NCMS resulted in an insignificant decrease in OOP\% by $1.4 \%$ across each survey cycle (every 3 years). Among other medical insurances, public insurance and private elder insurance had significant positive impacts on reimbursement ratio but did not influence OOP\%.

Conclusions: NCMS remarkably increased the rural elderly's reimbursement ratio but insignificantly decreased the rural elderly's OOP\%. In addition, the proportion of reimbursement ratio for NCMS participants increased by $6.4 \%$ every 3 years. Lower outpatient reimbursement, migration, limited reimbursement scope, an increasing demand for medical services and the rapid growth of medical expenses may be reasons for the gaps between the nominal reimbursement ratio and the actual reimbursement ratio and OOP\%. Policymakers should further modify NCMS policies in rural China.

Keywords: New cooperative medical scheme, Rural elderly, Health expenditures, Medical burden, Medical insurance

\footnotetext{
* Correspondence: fangya@xmu.edu.cn

${ }^{1}$ Key Laboratory of Health Technology Assessment of Fujian Province, School

of Public Health, Xiamen University, Xiang'an Nan Road, Xiang'an District,

Xiamen 361102, Fujian, China

Full list of author information is available at the end of the article
}

(c) The Author(s). 2019 Open Access This article is distributed under the terms of the Creative Commons Attribution 4.0 International License (http://creativecommons.org/licenses/by/4.0/), which permits unrestricted use, distribution, and reproduction in any medium, provided you give appropriate credit to the original author(s) and the source, provide a link to the Creative Commons license, and indicate if changes were made. The Creative Commons Public Domain Dedication waiver (http://creativecommons.org/publicdomain/zero/1.0/) applies to the data made available in this article, unless otherwise stated. 


\section{Background}

China is facing a serious challenge regarding aging. According to the sixth national census survey in 2010, China had 178 million people more than 60 years old and 119 million more than 65 years old, which accounted for 13.3 and $8.9 \%$ of its total population [1], respectively. The health of the elderly worsens with age, and elderly people typically suffer from many chronic diseases [2]. Elderly patients have complicated social, nutritional, and dependency needs; consequently, the problem of their ever-increasing medical expenses has become prominent, and the burden of degenerative disease has been imposed on the agenda at all levels of government [3]. The National Bureau of Statistics in China showed that the annual growth rate of medical expenses for elderly people aged 65 years and above was $2.7 \%$ between 1990 and 2010 and was projected to be $2.2 \%$ between 2010 to 2030, which exceeds that of the US and other OECD member countries (0.3-0.5\%).

The health of the rural elderly arouses great concern. The huge number of rural elderly and their deepening health problems (e.g., growing threats of infectious diseases and chronic diseases) place enormous pressure on health security for the elderly in rural China [4]. The subsidization of healthcare costs through insurance schemes is crucial in overcoming financial barriers to healthcare and avoiding high medical expenditures for patients in China [5]. In 2003, the Chinese central government launched a policy in rural areas called the 'New Cooperative Medical System' (NCMS). This scheme aims to safeguard farmers' access to basic health services and alleviate the financial burden caused by sickness and poverty with a focus on inpatient services and catastrophic outpatient services [6]. Farmers were actively encouraged to enroll in the scheme as over $70 \%$ of the NCMS fund was contributed by the government and individual contributions were relatively small. The participants are entitled to reimbursements in designated hospitals and regulated by lower reimbursement rates in higher-level hospitals.

The NCMS has been further adjusted and optimized to reduce health expenditures by rural residents and achieve universal coverage, and even though personal insurance premiums have been increasing, the reimbursement scope and proportion are also gradually expanding. The annual premium per capita has gradually increased from $¥ 40$ (\$4.88) in 2005 to $¥ 400$ (\$65.11) in 2014. In 2005, the coverage of NCMS was $21 \%$ throughout the entire nation. Reimbursement coverage mainly involved serious diseases, and the nominal reimbursement ratio for hospitalization was approximately 30\%. Outpatient expenditure coverage began in 2009. By the end of 2014, 736 million people had participated in the NCMS with a participation rate of $98.9 \%$. At the same time, the upper limit of reimbursement was also raised, with outpatient reimbursement increasing to $¥ 80$ (\$13.02), outpatient observation reaching $¥ 1000$ (\$162.79), and total medical service reaching $¥ 200,000$ $(\$ 32,557.38)$. In 2014, the nominal reimbursement ratio of hospitalization was $85 \%$ in township hospitals, $70 \%$ in county hospitals, $55 \%$ in municipal hospitals and $50 \%$ in provincial hospitals [5]. Through policy development of the NCMS, it is clear that the financing level and reimbursement of the NCMS have improved from 2005 to 2014. However, in 2011, the actual reimbursement ratio was far lower than the nominal reimbursement ratio of the NCMS plans [5].

The NCMS has been playing a growing and prominent role in alleviating the economic burden of farmers' medical treatment [7]. Since the founding of the NCMS in 2003, several studies have been conducted to evaluate its effectiveness in providing financial protection to rural residents and reduce health inequalities. Most studies suggest that NCMS had substantially improved health care access and utilization among the participants but offered limited financial protection in terms of out-of-pocket (OOP) health spending and catastrophic expenditure risk [8-10]. For instance, Cheng et al.'s study shows that NCMS helped alleviate inequalities in terms of perceived access to health care among rural elderly but did not reduce out-of-pocket spending [11]. Liu et al. proved that the effects of NCMS expansion have been offset by the rapid escalation of medical expenditures [12]. OOP spending remains a severe burden for rural patients [8]. Some other empirical studies also found that NCMS participants had a slightly lower chance of facing catastrophic medical expenditures but the results were not statistically significant $[13,14]$.

However, with the change of the proportion and the reimbursement scope of NCMS, few studies have used panel data to prove that a reduction in out-of-pocket spending by the NCMS, which is income-related, would relieve the disease-related financial burden for patients [11]. It is necessary to reexamine previous findings about the influence of NCMS on participants' health expenditures.

Therefore, this study aimed to 1) investigate the health expenditures and reimbursements of rural elderly people and 2) explore how the establishment and subsequent development of the NCMS influenced the medical financial burden of the Chinese rural elderly regarding OOP\% and reimbursements.

\section{Methods}

\section{Data sources}

This study is a quantitative study based on microscopic data of the Chinese Longitudinal Healthy Longevity Survey (CLHLS).We focused on the impact of compensation 
policy changes on the medical economic burden of the rural elderly after the establishment of the NCMS. Therefore, we used four sets of data $(2005,2008,2011$ and 2014) from the CLHLS. The CLHLS is a large-scale, multidisciplinary, longitudinal follow-up survey of the elderly. The baseline survey started in 1998 and covered individuals aged 65 and above in 801 counties of 22 Chinese provinces and cities $[15,16]$. Follow-up surveys of CLHLS were conducted in 2000, 2002, 2005, 2008-2009, 2011-2012, and 2014. Only the oldest (over 80 years) participants were surveyed before 2002, and health insurance coverage and healthcare expenditures were only asked since 2005 [11]; therefore, this study obtained samples from 2005 and subsequent waves for comparative analysis. Because we were concerned about the rural elderly, if the residential location was considered a rural area in the CLHLS four-wave data, then we included the data. The sample size was 7472 in the 2005 wave, 11,705 in the 2008-2009 wave, 9239 in the 2011-2012 wave, and 6059 in the 2014 wave.

\section{Variables}

\section{Dependent variables}

OOP payments included all categories of health-related expenses paid directly by the household at the time the household received health services and typically included doctors' consultation fees, medication purchases, and hospital bills [17]. However, insurance premiums were excluded because this study focused on measuring health expenditures directly related to illnesses. We calculated OOP\% as the individual payment for medical services divided by their per capita annual income last year. In addition, we focused on the reimbursement ratio, which was the medical expenses paid by the medical insurances last year divided by their total medical expenses last year, including inpatient and outpatient costs. The item 'Medical expenses paid by the family last year out of total medical costs' in the CLHLS questionnaire indicates that medical expenses paid by respondents themselves in the last year relative to those reimbursed by insurance.

\section{Independent variables}

According to Grossman health demand theory [18, 19], we considered individuals' socioeconomic characteristics, pensions and insurance and health service demand and utilization as independent variables. Basic personal information included gender, marital status, age, self-rated economic status, education, occupation before 60 , family number, family total income in the past year. Health service demand and utilization included self-reported health, serious illnesses within the last 2 years, receipt of adequate medical service, medical service costs, and family expenses for medical services. Pension and insurance included retirement pension, public and free medical services, private or commercial elderly insurance, public elderly insurance, other social security or private insurance, the NCMS, and commercial medical insurance.

The variable of marital status was divided into the categories 'currently married' and 'living with spouse', and nonmarital status included the categories 'divorced', 'widowed' and 'never married.' The variable 'serious illnesses within the last two years' was changed into a dichotomous variable with ' 0 ' and ' 1 ', which represented the subject suffering from serious illness one or more times. 'Occupation' was a dummy variable that was ' 0 ' for formal occupations, ' 1 ' for self-employment and ' 2 ' for no work. 'Self-rated economic status' and 'self-reported health' were ordered multicategorized variables in which ' 1 ' to ' 5 ' represented 'very well' to 'very bad.'

Considering the time value of money, we multiplied the 'medical service costs,' 'medical service costs paid by family' and 'family total income' of 2005, 2008, and 2011 by the inflation factor, which is $8 \%$ per year [20]. The exchange rate of the US dollar to RMB was 8.192 in 2005, 6.945 in 2008, 6.459 in 2011 and 6.143 in 2014.

\section{Analysis methods}

In the past, researchers that performed empirical studies using more than two waves of the CLHLS usually deleted all censoring identification, which led to survivor bias [21]. This study was particularly focused on rural elderly people who spend a lot on medical care. These people are sensitive to price, and when in need of expensive healthcare they were likely to decline treatment, which results in shorter lives. Therefore, survivor bias would harm our results. To avoid survivor bias, this study selected IDs with two or more observations within the four waves, which constructed an unbalanced panel dataset.

We use a static two-equation seemingly unrelated regression (SUR) model framework for unbalanced panel data with latent individual heterogeneity and the reimbursement ratio and OOP\% as endogenous variables [22-24]. The seemingly unrelated regressions (SUR) model explains the variation of not just one dependent variable, as in the univariate multiple regression model, but the variation of a set of many dependent variables [25]. SUR estimators performed consistently better than ordinary least squares (OLS) estimators since SUR takes the correlation between error terms into account [26].

All of the model versions we considered contained two equations, which had linear coefficients and were compactly written as $y_{g i t}=\mathrm{xg}_{i t}+\mathrm{g}_{\mathrm{i}}+u \mathrm{~g}_{\mathrm{it}}$, where $\mathrm{g}$ is the equation number $(g=1$ represents reimbursement ratio and $g=2$ represents OOP\%), $i$ is the ID number, and $t$ is the number of periods in which the ID was observed. 
The approach for this method is based on the construction of a multistep (stepwise) algorithm using the generalized least squares and maximum likelihood procedures. Based on this method, we built eq. 1 for OOP\% endogenous variables and exogenous variables: the characteristics of sociology (except family number and total income), pension and insurance, and medical service demand and utilization (except family pay for medical services). We constructed eq. 2 for the following reimbursement ratio endogenous variables and exogenous variables: sociodemographic characteristics, pension and insurance, and medical service demand and utilization. Variables were filtered through the stepwise method to retain meaningful exogenous variables. All analyses were performed using Stata SE 15.1 (Stata Corp; College Station, TX).

\section{Results}

The age, gender, marital status, occupation, degree of education and self-assessed economic status of Chinese rural elderly people between 2005 and 2014 are summarized in Table 1. In 2005, 81.94\% of respondents reported that their economic status was so-so or better, and by 2014 , that proportion rose to $87.20 \%$. Hence, the household incomes per capita grew rapidly and self-rated economic status improved. The average age of the respondents increased from 81.11 to 84.99 years. The rural elderly who had serious illnesses once or more within the last 2 years increased from $16.31 \%$ in 2005 to $24.57 \%$ in 2014 . The increase in the incidence of serious illness could at least partially be explained by the steady increase in mean age and aging structure of the population.

Fortunately, and with the development of primary healthcare, the proportion of patients who did not receive timely medical care decreased to only $3.99 \%$. However, the health status of rural elderly also declined over the past decade. In 2005, more than half of the elderly believed they were in good or very good health, which was down to approximately 43\% in 2014 . Self-reported health and the number of serious diseases reflect the medical service demand of rural elderly people. As descriptive statistics of pensions and insurance demonstrates, the number of rural elderly with public elderly insurance and NCMS increased dramatically between 2005 and 2014. The NCMS coverage increased from $11.63 \%$ in 2005 to $80.34 \%$ in 2014 . The coverage of public elder insurance expanded from $3.72 \%$ in 2005 to $27.1 \%$ in 2014 but other forms of pensions and insurance did not significantly change.

Table 2 shows the medical service cost and reimbursement ratio for the rural elderly. The average number of family members decreased while the total household incomes increased sharply from \$895.26 in 2005 to
$\$ 4541.92$ in 2014. In addition, the medical expenses of the elderly also increased from an average of $\$ 204.77$ in 2005 to $\$ 696.23$ in 2014 , which was more than three times as much as in 2005. Thus, even with the rapid promotion of medical service costs the total household income was growing faster. The reimbursement ratio for the medical expenses of rural elderly people with NCMS increased significantly from $23.6 \%$ in 2005 to $56.1 \%$ in 2014. OOP\% remained at approximately $20 \%$ during the 10 years.

Table 3 presents the influencing factors of OOP\% and reimbursement ratio selected by the SUR model. In 2005 , the variable 'other social security or private insurance' was more than $90 \%$ missing and therefore wasn't included in the regression equation. As the result of the OOP\% equation showed, the regression coefficient of the NCMS was positive but not significant, which indicated that the OOP\% was reduced slightly by NCMS. Among the sociodemographic characteristic variables, rural elderly people who were married had a poor self-rated economic status and formal occupation before 60 had a higher OOP\%. Among medical service demand and utilization variables, rural elderly with a higher OOP\% suffered from poor health status and serious illnesses in the last 2 years and spent a lot on medical services. The higher OOP\% usually did not have retirement wages or pensions.

According to the second part of Table 3, the NCMS could significantly increase the reimbursement ratio. Among rural old people, widowed or divorced younger elderly women with poor economic conditions, a low educational level, formal occupation before 60, and a larger family had a lower reimbursement ratio. Formal occupations in this study included technicians/doctors/ teachers, managers, general staff/servicer/workers, and military. Compared to freelancers, farmers, domestic workers or the unemployed, the reimbursement ratio of formal professionals was lower and the OOP\% was higher. The proportion of reimbursement ratio for rural seniors with NCMS increased by $6.4 \%$ across each survey cycle (every 3 years). The proportion of reimbursement for the elderly without retirement wages, pensions, public medical insurance, NCMS and private medical insurance was lower. In addition, rural seniors whose self-report health status was poor suffered from serious illness last year and could get adequate medical service with a higher OOP\%.

\section{Discussion}

Since the founding of the NCMS in 2003, personal insurance premiums have been increasing and the reimbursement scope and proportion are also gradually expanding. This study mainly focused on the developing period of the NCMS. We found that the NCMS 
Table 1 Statistical description of demographic characteristics

\begin{tabular}{|c|c|c|c|c|}
\hline \multirow[t]{2}{*}{ Description } & \multirow{2}{*}{$\begin{array}{l}2005 \\
(N=7472) \\
n(\%)\end{array}$} & \multirow{2}{*}{$\begin{array}{l}2008 \\
(N=11,705) \\
n(\%)\end{array}$} & \multirow{2}{*}{$\begin{array}{l}2011 \\
(N=9239) \\
n(\%)\end{array}$} & \multirow{2}{*}{$\begin{array}{l}2014 \\
(N=6059) \\
n(\%)\end{array}$} \\
\hline & & & & \\
\hline Age (year) & $81.11 \pm 10.78$ & $84.14 \pm 11.31$ & $85.15 \pm 11.17$ & $84.99 \pm 10.55$ \\
\hline Family number & $2.90 \pm 1.89$ & $2.75 \pm 1.87$ & $2.80 \pm 2.14$ & $2.43 \pm 1.94$ \\
\hline \multicolumn{5}{|l|}{ Gender } \\
\hline male & $2456(45.04)$ & $3930(44.62)$ & $3346(45.24)$ & $2369(46.29)$ \\
\hline female & $2997(54.96)$ & 4877 (55.38) & $4050(54.76)$ & $2749(53.71)$ \\
\hline \multicolumn{5}{|l|}{ Category of residence } \\
\hline city and town & $1065(19.53)$ & $1815(20.61)$ & $2698(36.48)$ & $2810(54.90)$ \\
\hline rural & $4388(80.47)$ & $6992(79.39)$ & $4698(63.52)$ & $2308(45.10)$ \\
\hline \multicolumn{5}{|l|}{ Main occupation before age 60} \\
\hline formal occupations & $20(0.37)$ & $26(0.30)$ & $20(0.27)$ & $12(0.26)$ \\
\hline self-employment & $5092(93.64)$ & $8285(94.28)$ & $6990(94.91)$ & $4324(95.05)$ \\
\hline no work & $326(6.00)$ & $477(5.43)$ & $355(4.82)$ & $213(4.68)$ \\
\hline \multicolumn{5}{|l|}{ Current marital status } \\
\hline nonmarital status & $3128(57.36)$ & $5398(61.29)$ & $4464(60.95)$ & $2933(58.88)$ \\
\hline currently married & $2325(42.64)$ & $3409(38.71)$ & $2860(39.05)$ & $2048(41.12)$ \\
\hline \multicolumn{5}{|l|}{ Education } \\
\hline primary school & $3411(62.74)$ & $5529(62.94)$ & $4513(61.20)$ & $2961(57.98)$ \\
\hline middle school and above & $1364(25.09)$ & $2067(23.53)$ & $1751(23.75)$ & $2146(42.02)$ \\
\hline \multicolumn{5}{|l|}{ Self-rated economic status } \\
\hline very rich & $51(0.94)$ & $69(0.79)$ & $83(1.14)$ & $67(1.35)$ \\
\hline rich & $746(13.74)$ & 979 (11.14) & $1123(15.43)$ & $710(14.26)$ \\
\hline fair & $3653(67.26)$ & $5986(68.12)$ & $4873(66.96)$ & $3566(71.61)$ \\
\hline poor & $835(15.38)$ & $1449(16.49)$ & $969(13.31)$ & $521(10.46)$ \\
\hline very poor & $146(2.69)$ & $305(3.47)$ & $230(3.16)$ & $116(2.34)$ \\
\hline \multicolumn{5}{|c|}{ Serious illness within the past two years } \\
\hline 0 & $4561(83.69)$ & $7465(84.77)$ & $5778(79.53)$ & $3650(75.43)$ \\
\hline $1 \sim$ & $889(16.31)$ & $1341(15.23)$ & $1487(20.47)$ & $1189(24.57)$ \\
\hline \multicolumn{5}{|l|}{ Self-reported health } \\
\hline very good & $591(11.25)$ & $909(11.24)$ & $653(9.47)$ & $402(8.51)$ \\
\hline good & $2205(41.98)$ & $3108(38.43)$ & $2422(35.11)$ & $1647(34.86)$ \\
\hline so-so & $1710(32.56)$ & $2717(33.60)$ & $2607(37.79)$ & $1891(40.02)$ \\
\hline bad & $690(13.14)$ & $1243(15.37)$ & $1119(16.22)$ & $694(14.69)$ \\
\hline very bad & $56(1.07)$ & $110(1.36)$ & $98(1.42)$ & $91(1.93)$ \\
\hline \multicolumn{5}{|l|}{ Get adequate medical service } \\
\hline yes & $4772(87.51)$ & $8043(91.33)$ & $6832(93.38)$ & $4787(96.01)$ \\
\hline no & $681(12.49)$ & $764(8.68)$ & $484(6.62)$ & $199(3.99)$ \\
\hline \multicolumn{5}{|l|}{ Retirement pension } \\
\hline yes & $475(8.71)$ & $677(7.69)$ & $629(8.75)$ & $510(11.00)$ \\
\hline no & $4978(91.29)$ & $8130(92.31)$ & $6563(91.25)$ & $4126(89.00)$ \\
\hline \multicolumn{5}{|l|}{ Public free medical services } \\
\hline yes & $172(3.15)$ & $271(3.08)$ & $169(2.35)$ & $96(2.08)$ \\
\hline no & $5281(96.85)$ & $8536(96.92)$ & $7038(97.66)$ & $4514(97.92)$ \\
\hline
\end{tabular}


Table 1 Statistical description of demographic characteristics (Continued)

\begin{tabular}{|c|c|c|c|c|}
\hline \multirow[t]{2}{*}{ Description } & $\begin{array}{l}2005 \\
(N=7472)\end{array}$ & $\begin{array}{l}2008 \\
(N=11,705)\end{array}$ & $\begin{array}{l}2011 \\
(N=9239)\end{array}$ & $\begin{array}{l}2014 \\
(N=6059)\end{array}$ \\
\hline & $n(\%)$ & $n(\%)$ & $n(\%)$ & $n(\%)$ \\
\hline \multicolumn{5}{|c|}{ Private or commercial elder insurance } \\
\hline yes & $31(0.57)$ & $17(0.19)$ & $78(1.08)$ & $36(0.78)$ \\
\hline no & $5422(99.43)$ & $8790(99.81)$ & $7128(98.92)$ & $4571(99.22)$ \\
\hline \multicolumn{5}{|c|}{ Public elder insurance } \\
\hline yes & $203(3.72)$ & $366(4.16)$ & $1316(18.23)$ & $1262(27.11)$ \\
\hline no & $5250(96.28)$ & $8441(95.84)$ & $5904(81.77)$ & $3393(72.89)$ \\
\hline \multicolumn{5}{|c|}{ Other social security or private insurance } \\
\hline yes & $125(82.78)$ & $261(2.97)$ & $272(4.15)$ & $159(3.78)$ \\
\hline no & $26(17.22)$ & $8541(97.04)$ & $6279(95.85)$ & $4053(96.23)$ \\
\hline \multicolumn{5}{|l|}{ NCMS } \\
\hline yes & $634(11.63)$ & $5340(60.63)$ & $5767(79.10)$ & $3947(80.34)$ \\
\hline no & $4819(88.37)$ & $3467(39.37)$ & $1524(20.90)$ & $966(19.66)$ \\
\hline \multicolumn{5}{|c|}{ Commercial medical insurance } \\
\hline yes & $52(0.95)$ & $29(0.33)$ & $25(0.35)$ & $46(1.00)$ \\
\hline no & 5401 (99.05) & 8778 (99.67) & 7176 (99.65) & 4571 (99.00) \\
\hline
\end{tabular}

coverage was $11.6 \%$ in 2005 and increased to $80.3 \%$ in 2014. With the promotion of coverage and the change of insurance, the NCMS could effectively and significantly elevate the actual reimbursement ratio of the medical financial burden of Chinese rural seniors. This finding is in line with an existing study by Wang et al. [27]. From 2005 to 2014, the reimbursement ratio for medical expenses of rural elderly people with NCMS increased significantly from $30.6 \%$ in 2005 to $56.1 \%$ in 2014 . In addition, the proportion of reimbursement ratio for rural seniors with NCMS increased by $6.4 \%$ across each survey cycle (every 3 years). However, the NCMS resulted in an insignificant decrease in OOP\% by $1.4 \%$ across each survey cycle (every 3 years). Among other medical insurances, public insurance and private elder insurance had significant positive impacts on reimbursement ratio but did not influence OOP\%. The innovation of this study was that it considered truncated data and effectively avoided survivor bias.

In 2014, the NCMS stipulated that the reimbursement ratio varied from $50 \%$ at provincial hospitals to $85 \%$ at township hospitals. According to the results of this study, the actual reimbursement ratio of the rural elderly with the NCMS as the main medical insurance was only $56 \%$ in 2014 , which was the highest proportion in the past decade. Previous studies also found that effective reimbursement ratio of both outpatient and inpatient services were much lower than nominal reimbursement ratio that were originally designed by NCMS plans [5].

There may be several reasons for the gap between the nominal reimbursement ratio and the actual reimbursement ratio and $\mathrm{OOP} \%$, which was not significantly decreased by the NCMS. First, the low reimbursement ratio of the outpatient service in the NCMS was one of the reasons why the medical burden of the rural elderly has not been reduced. Of the total available NCMS funds, $70 \%$ were allocated to inpatient reimbursements and $30 \%$ to outpatient services [28]. The NCMS set an upper limit for outpatient reimbursement. These regulations made farmers' benefits less extensive. An early empirical study also found that medical expenditures for outpatient services significantly increased for chronic

Table 2 Medical expenses and the reimbursement of rural elderly with NCMS

\begin{tabular}{|c|c|c|c|c|}
\hline \multirow[t]{2}{*}{ DESCRIPTION } & \multicolumn{4}{|l|}{ Mean \pm SD } \\
\hline & 2005 & 2008 & 2011 & 2014 \\
\hline Medical service costs in total (\$) & $204.77 \pm 588.57$ & $271.81 \pm 921.35$ & $510.37 \pm 1727.389$ & $696.23 \pm 1866.99$ \\
\hline Personal pay for medical services $(\$)$ & $185.53 \pm 551.64$ & $226.99 \pm 765.34$ & $359.20 \pm 1068.68$ & $177.81 \pm 534.99$ \\
\hline Family total income $(\$)$ & $895.26 \pm 1642.11$ & $2972.74 \pm 3449.97$ & $4196.31 \pm 4752.87$ & $4541.92 \pm 4693.29$ \\
\hline ООР\% $\%(\%)$ & $18.2 \pm 29.1$ & $26.1 \pm 33.6$ & $25.7 \pm 36.6$ & $17.6 \pm 28.7$ \\
\hline Reimbursement ratio (\%) & $23.6 \pm 41.3$ & $24.9 \pm 40.4$ & $43.2 \pm 44.5$ & $56.1 \pm 42.1$ \\
\hline
\end{tabular}


Table $\mathbf{3}$ Influence factors of OOP\% and reimbursement by SUR

\begin{tabular}{|c|c|c|c|c|}
\hline & Coef. & $\mathrm{Sd}$ & z & $P>\mid z$ \\
\hline \multicolumn{5}{|l|}{$\mathrm{OOP} \%$} \\
\hline Residence & 0.062 & 0.008 & 7.600 & 0.000 \\
\hline Gender & 0.006 & 0.009 & 0.730 & 0.464 \\
\hline Marriage & 0.041 & 0.009 & 4.280 & 0.000 \\
\hline Age & 0.000 & 0.000 & -0.700 & 0.486 \\
\hline Economics & 0.064 & 0.006 & 10.920 & 0.000 \\
\hline Education & -0.010 & 0.006 & -1.480 & 0.140 \\
\hline Occupation 1 (refer to formal occupations) & -0.196 & 0.045 & -4.360 & 0.000 \\
\hline Occupation 2 (refer to formal occupations) & -0.221 & 0.049 & -4.520 & 0.000 \\
\hline Retirement wage & -0.066 & 0.015 & -4.340 & 0.000 \\
\hline Pension & -0.046 & 0.011 & -4.130 & 0.000 \\
\hline Public insurance & -0.056 & 0.032 & -1.730 & 0.083 \\
\hline Commercial medical insurance & 0.003 & 0.067 & 0.040 & 0.968 \\
\hline NCMS & -0.014 & 0.009 & -1.540 & 0.124 \\
\hline Private elder insurance & -0.015 & 0.049 & -0.300 & 0.761 \\
\hline Self-reported health & 0.046 & 0.004 & 10.590 & 0.000 \\
\hline Serious illness times & 0.187 & 0.011 & 17.450 & 0.000 \\
\hline Get adequate medical service & 0.005 & 0.014 & 0.360 & 0.719 \\
\hline Medical service costs & 0.000 & 0.000 & 17.370 & 0.000 \\
\hline \multicolumn{5}{|l|}{ Reimbursement ratio } \\
\hline Residence & -0.073 & 0.006 & -12.250 & 0.000 \\
\hline Gender & -0.022 & 0.006 & -3.410 & 0.001 \\
\hline Marriage & 0.024 & 0.007 & 3.550 & 0.000 \\
\hline Age & 0.002 & 0.000 & 8.260 & 0.000 \\
\hline Economics & -0.020 & 0.004 & -4.490 & 0.000 \\
\hline Education & 0.013 & 0.005 & 2.800 & 0.005 \\
\hline Occupation 1 (refer to formal occupations) & 0.434 & 0.033 & 13.310 & 0.000 \\
\hline Occupation 2 (refer to formal occupations) & 0.391 & 0.035 & 11.050 & 0.000 \\
\hline Family number & -0.009 & 0.002 & -5.550 & 0.000 \\
\hline Family total income & 0.000 & 0.000 & -1.040 & 0.296 \\
\hline Retirement wage & 0.070 & 0.011 & 6.280 & 0.000 \\
\hline Pension & 0.076 & 0.008 & 9.420 & 0.000 \\
\hline Public insurance & 0.171 & 0.023 & 7.290 & 0.000 \\
\hline Commercial medical insurance & 0.063 & 0.049 & 1.290 & 0.196 \\
\hline NCMS & 0.064 & 0.006 & 9.910 & 0.000 \\
\hline Private elder insurance & 0.114 & 0.036 & 3.200 & 0.001 \\
\hline Self-reported health & -0.023 & 0.003 & -7.300 & 0.000 \\
\hline Serious illness times & -0.019 & 0.007 & -2.610 & 0.009 \\
\hline Get adequate medical service & -0.068 & 0.010 & -6.920 & 0.000 \\
\hline
\end{tabular}

disease patients [12]. Among people who had at least one outpatient visit during the past month, people with NCMS tend to have the highest OOP payments [29].

Second, during the 10 years of the survey, some respondents migrated from rural areas to cities. Of the respondents we screened, $19.53 \%$ lived in cities in 2005 , which rose to $54.9 \%$ by 2014 . The NCMS financing did not achieve national unification and therefore migrants may not be able to obtain reimbursement for medical treatment in other places, which results in a higher 
OOP\% of their own medical expenditures. A previous study regarding the impact of NCMS on migrants showed that $55.2 \%$ of migrants in comparison with $24.6 \%$ of nonmigrants received no reimbursement from the NCMS [30]. Until the beginning of 2017, when the National Health Planning Commission issued a NCMS cross-provincial settlement reimbursement policy, this problem was unresolved. However, the effect of the solution remains to be verified.

Third, due to the low level of financing of NCMS, the limited compensation scope of NCMS may also be a reason. Ma et al. also found that a limited benefit package excluding many drugs or medical checks mainly resulted in high OOP spending and a considerable gap between the effective reimbursement ratio and the nominal reimbursement ratio [5]. The list of basic drugs was limited, and some expensive new drugs were not in the expense account. Injury has become the second leading cause of death in China, but the NCMS reimbursement excludes some accidental injuries, which indicates that these patients must pay for themselves. In recent years, new medical technology gradually entered the hospital. The NCMS only reimburses 200 yuan (at most) for Computed tomography (CT), Magnetic resonance imaging (MRI) and other auxiliary examinations, which makes the insured more self-sufficient.

Finally, an increasing demand for medical services and the rapid growth of medical expenses may also be an important reason. According to our results, the medical expenses of the rural elderly increased from an average of $\$ 204.77$ in 2005 to $\$ 696.23$ in 2014, which was more than three times as much as in 2005. The effects of the NCMS expansion have been offset by the rapid escalation of medical expenditures [12]. From 2005 to 2014, the self-assessed health level of the elderly in rural China gradually declined, which is possibly associated with higher social expectations. In addition, the number of serious diseases increased; therefore, the demand for medical services continued to increase. As the results of the regression model of OOP\% and reimbursement ratio showed, rural elderly with poor health and serious illness in the past year had higher OOP\% and a lower reimbursement ratio.

Therefore, we suggest that future NCMS policy revisions should maintain reimbursement ratio at their current levels. We can only effectively reduce the proportion of self-payments and the medical financial burdens of rural elderly people by controlling medical expenses. The financial protection of NCMS with average reimbursements of $56.1 \%$ in 2014 was modest and should be restructured to provide better benefits targeted for those with the most need [31].

According to the regression results of the two endogenous variables, rural elderly people with relatively poor economic conditions and poor health levels have higher OOPs and lower reimbursement ratio. Poor and unhealthy rural elderly people are at high medical financial risk. A study by Lai et al. also found that the benefits of NCMS are concentrated toward economically affluent groups [32]. Unreasonably increasing health expenses have aggravated the medical financial burden of low-income households [5]. In the NCMS, the pro-rich inequality dominated for inpatient care, while there was also a pro-poor advantage [33]. Rural people who haven't benefitted from China's economic development may not benefit from the recent healthcare reform and finance mechanisms unless schemes, such as the NCMS, provide more substantial subsidies [34]. The impact of NCMS in demoting medical service expenses of rural residents is still limited. The government should set up corresponding medical assistance to prevent poverty in these people.

There were some limitations in this study. First, with the rapid growth of NCMS coverage, we were unable to compare the medical expenses of elderly people with or without NCMS and failed to identify mutual factors influencing OOP\% for all rural elderly people. Second, changes in health insurance for migrants from rural to urban areas have not been included. For instance, in 2014, some interviewees failed to report their hospitalization expense reimbursements to CLHLS in time, which may lead to lower OOP\% and higher reimbursement ratio than the actual situation. Therefore, the financial protection effect of NCMS may be exaggerated.

\section{Conclusion}

NCMS could remarkably increase the rural elderly's reimbursement ratio but insignificantly promote the rural elderly's OOP\%. The proportion of reimbursement ratio for rural seniors with NCMS increased by $6.4 \%$ every 3 years. There may be several reasons for the gap between the nominal reimbursement ratio and actual reimbursement ratio and $\mathrm{OOP} \%$, which was not significantly reduced by the NCMS. These reasons may include lower outpatient reimbursement, migration, a limited reimbursement scope, an increasing demand for medical services and the rapid growth of medical expenses. Policymakers should further modify NCMS policies in rural China. Rural elderly people with relatively poor economic conditions and poor health levels have higher OOPs and lower reimbursement ratio. The government should implement corresponding medical assistance to prevent poverty among these people.

\section{Abbreviations}

CLHLS: Chinese Longitudinal Healthy Longevity Survey; CT: Computed tomography; MRI: Magnetic resonance imaging; NCMS: New Cooperative Medical Scheme; OOP: out-of-pocket; SUR: seemingly unrelated regression

Acknowledgements

The authors would like to thank all the respondents of CLHLS for their cooperation. 


\section{Funding}

This paper is supported by National Natural Science Foundation of China [Grant NO. 71874147, 81573257] and the project of Natural Science Fund of Fujian Province [Grant 2017 J01133]. The funders had no role in study design, data collection and analysis, decision to publish or preparation of the manuscript.

\section{Availability of data and materials}

The CLHLS dataset is publicly available. Information about the data source and available data are found at https://www.icpsr.umich.edu/icpsrweb/ DSDR/studies/36179.

\section{Authors' contributions}

$Y F$ and $Y Z$ developed the study design. $Y Z$ and $J$ performed the statistical analysis. $Y Z, J L$ and $Z Y$ participated in the analysis and interpretation of the data and drafted the manuscript. All authors contributed to the editing the manuscript. All authors read and approved the final manuscript.

\section{Ethics approval and consent to participate}

The CLHLS study was approved by research ethics committees of Duke University and Peking University (IRB00001052-13074). All participants provided written informed consent. No experimental interventions were performed.

\section{Consent for publication}

Not applicable.

\section{Competing interests}

The authors declare that they have no competing interests.

\section{Publisher's Note}

Springer Nature remains neutral with regard to jurisdictional claims in published maps and institutional affiliations.

\section{Author details}

${ }^{1}$ Key Laboratory of Health Technology Assessment of Fujian Province, School of Public Health, Xiamen University, Xiang'an Nan Road, Xiang'an District, Xiamen 361102, Fujian, China. ${ }^{2}$ Center for Health Economics Experiment and Public Policy, School of Public Health, Shandong University, Jinan, China.

\section{Received: 22 July 2018 Accepted: 28 January 2019}

\section{Published online: 06 February 2019}

\section{References}

1. National Bureau of Statistics of China. Communiqué of the National Bureau of Statistics of People's Republic of China on Major Figures of the 2010 Population Census (No. 1). Available from: [http://www.stats.gov.cn/english/ Statisticaldata/CensusData/rkpc2010/indexch.htm].

2. Xian-xin Z. A comprehensive analysis of the health of China's elderly population. Popul Econ. 2010:5:014.

3. Woo J, Kwok T, Sze FK, Yuan HJ. Ageing in China: health and social consequences and responses. Int J Epidemiol. 2002;31:772-5. https://doi. org/10.1093/ije/31.4.772.

4. Dai B. The old age health security in rural China: where to go? Int J Equity Health. 2015;14:119. https://doi.org/10.1186/s12939-015-0224-5.

5. Ma J, Xu J, Zhang Z, Wang J. New cooperative medical scheme decreased financial burden but expanded the gap of income-related inequity: evidence from three provinces in rural China. Int J Equity Health. 2016;15:72. https://doi.org/10.1186/s12939-016-0361-5.

6. General Office of the State Council of the People's Republic of China. The State Council forwards the notice released by the Ministry of Health regarding the establishment of the New Cooperative Scheme for rural areas. Available from: [http://www.gov.cn/zwgk/2005-08/12/ content_21850.htm].

7. Dai T, Hu HP, Na X, Li YZ, Wan YL, Xie LQ. Effects of new rural cooperative medical scheme on medical service utilization and medical expense control of inpatients: a 3-year empirical study of Hainan Province in China. Chin Med J. 2016:129:1280-4. https://doi.org/10.4103/0366-6999.182842.

8. Sun X, Sleigh AC, Carmichael GA, Jackson S. Health payment-induced poverty under China's new cooperative medical scheme in rural Shandong. Health Policy Plan. 2010;25:419-26. https://doi.org/10.1093/heapol/czq010.
9. You X, Kobayashi Y. The new cooperative medical scheme in China. Health Policy. 2009;91:1-9. https://doi.org/10.1016/j.healthpol.2008.11.012.

10. Yu B, Meng Q, Collins C, Tolhurst R, Tang S, Yan F, Bogg L, Liu X. How does the new cooperative medical scheme influence health service utilization? A study in two provinces in rural China. BMC Health Serv Res. 2010;10:116. https://doi.org/10.1186/1472-6963-10-116.

11. Cheng $L$, Liu H, Zhang Y, Shen K, Zeng Y. The impact of health insurance on health outcomes and spending of the elderly: evidence from China's new cooperative medical scheme. Health Econ. 2015;24:672-91. https://doi. org/10.1002/hec.3053.

12. Liu X, Sun $X$, Zhao Y, Meng Q. Financial protection of rural health insurance for patients with hypertension and diabetes: repeated cross-sectional surveys in rural China. BMC Health Serv Res. 2016;16:481. https://doi.org/10. 1186/s12913-016-1735-5

13. Zhang L, Li S, Yi H, d'Intignano LM, Ding Y. Correlation between new cooperative medical scheme policy design and catastrophic medical payment: evidence from 25 counties in rural China. Asia Pac J Public Health. 2016;28:26-38. https://doi.org/10.1177/1010539515612907.

14. Sun Q, Liu X, Meng Q, Tang S, Yu B, Tolhurst R. Evaluating the financial protection of patients with chronic disease by health insurance in rural China. Int J Equity Health. 2009:8:42. https://doi.org/10.1186/1475-9276-8-42.

15. Smith JP. Healthy bodies and thick wallets: the dual relation between health and economic status. J Econ Perspect. 1999;13:145-66. https://doi.org/10. 1257/jep.13.2.145

16. Ettner SL. New evidence on the relationship between income and health. J Health Econ. 1996:15:67-85. https://doi.org/10.1016/0167-6296(95)00032-1.

17. Van Minh H, Kim Phuong NT, Saksena P, James CD, Xu K. Financial burden of household out-of pocket health expenditure in Viet Nam: findings from the National Living Standard Survey 2002-2010. Soc Sci Med. 2013;96:258-63. https://doi.org/10.1016/j.socscimed.2012.11.028.

18. Bolin $K$, Lindgren $B$, Lindström $M$, Nystedt $P$. Investments in social capital-implications of social interactions for the production of health. Soc Sci Med. 2003;56:2379-90. https://doi.org/10.1016/s0277-9536(02)00242-3.

19. Tabata K, Ohkusa Y. Correction note on "the demand for health with uncertainty and insurance". J Health Econ. 2000;19:811-20. https://doi.org/ 10.1016/s0167-6296(00)00036-9.

20. Shen P, Zhang J. The research on social discount rate applied in costbenefit analysis for public health project. Chinese Health Econ. 2010;6:72-3.

21. Han WJ, Shibusawa T. Trajectory of physical health, cognitive status, and psychological well-being among Chinese elderly. Arch Gerontol Geriatr. 2015;60:168-77. https://doi.org/10.1016/j.archger.2014.09.001.

22. Biørn E. Estimating SUR system with random coefficients: the unbalanced panel data case. Empir Econ. 2013;47:451-68. https://doi.org/10.1007/ s00181-013-0753-y.

23. Biørn E. Regression systems for unbalanced panel data: a stepwise maximum likelihood procedure. J Econ. 2004;122:281-91. https://doi.org/10. 1016/j.jeconom.2003.10.023.

24. Wangen KR, Biørn E. Individual heterogeneity and price responses in tobacco consumption: a two-commodity analysis of unbalanced panel data; 2001.

25. Zellner A. An efficient method of estimating seemingly unrelated regressions and tests for aggregation Bias. J Am Stat Assoc. 1962:57:348-68. https://doi.org/10.1080/01621459.1962.10480664.

26. Keshavarzi S, Ayatollahi SM, Zare N, Sharif F. Quality of life of childbearing age women and its associated factors: an application of seemingly unrelated regression (SUR) models. Qual Life Res. 2013;22:1255-63. https:// doi.org/10.1007/s11136-012-0250-3.

27. Wang L, Wang A, FitzGerald G, Si L, Jiang Q, Ye D. Who benefited from the new rural cooperative medical system in China? A case study on Anhui Province. BMC Health Serv Res. 2016:16:195. https://doi.org/10.1186/s12913-016-1441-3.

28. Sun X, Jackson S, Carmichael GA, Sleigh AC. Prescribing behaviour of village doctors under China's new cooperative medical scheme. Soc Sci Med. 2009; 68:1775-9. https://doi.org/10.1016/.j.socscimed.2009.02.043.

29. Li $X$, Zhang $W$. The impacts of health insurance on health care utilization among the older people in China. Soc Sci Med. 2013;85:59-65. https://doi. org/10.1016/j.socscimed.2013.02.037.

30. Qiu P, Yang Y, Zhang J, Ma X. Rural-to-urban migration and its implication for new cooperative medical scheme coverage and utilization in China. BMC Public Health. 2011;11:520. https://doi.org/10. 1186/1471-2458-11-520

31. Sun X, Jackson S, Carmichael G, Sleigh AC. Catastrophic medical payment and financial protection in rural China: evidence from the new cooperative 
medical scheme in Shandong Province. Health Econ. 2009;18:103-19. https://doi.org/10.1002/hec.1346.

32. Lai S, Shen C, Xu Y, Yang X, Si Y, Gao J, Zhou Z, Chen G. The distribution of benefits under China's new rural cooperative medical system: evidence from western rural China. Int J Equity Health. 2018;17:137. https://doi.org/10. 1186/s12939-018-0852-7.

33. Yuan S, Rehnberg C, Sun X, Liu X, Meng Q. Income related inequalities in new cooperative medical scheme: a five-year empirical study of Junan County in China. Int J Equity Health. 2014;13:38. https://doi.org/10.1186/ 1475-9276-13-38.

34. Mahmood MA, Raulli A, Yan W, Dong H, Aiguo Z, Ping D. Cooperative medical insurance and the cost of care in Shandong, PR China: perspectives of patients and community members. Asia Pac J Public Health. 2015;27: NP897-902. https://doi.org/10.1177/1010539510376664.

Ready to submit your research? Choose BMC and benefit from:

- fast, convenient online submission

- thorough peer review by experienced researchers in your field

- rapid publication on acceptance

- support for research data, including large and complex data types

- gold Open Access which fosters wider collaboration and increased citations

- maximum visibility for your research: over $100 \mathrm{M}$ website views per year

At BMC, research is always in progress.

Learn more biomedcentral.com/submissions 